\title{
Study on Comprehensive Value of Industrial Heritage in Yuejin Road Historic District Based on GIS Technology
}

\author{
Pan Zhang1, Mingming Xiang ${ }^{*}$, Tao Zhang2, Yujie Yao ${ }^{1}$ \\ ${ }^{1}$ School of Civil Engineering and Architecture, Southwest University of Science and Technology, Mianyang, China \\ ${ }^{2}$ School of Foreign Language, Southwest Forestry University, Kunming, China \\ Email: ${ }^{\star 763351554 @ q q . c o m ~}$
}

How to cite this paper: Zhang, P., Xiang, M. M., Zhang, T., \& Yao, Y. J. (2021). Study on Comprehensive Value of Industrial Heritage in Yuejin Road Historic District Based on GIS Technology. Open Journal of Social Sciences, 9, 440-454.

https://doi.org/10.4236/jss.2021.95024

Received: April 30, 2021

Accepted: May 22, 2021

Published: May 25, 2021

Copyright () 2021 by author(s) and Scientific Research Publishing Inc. This work is licensed under the Creative Commons Attribution International License (CC BY 4.0).

http://creativecommons.org/licenses/by/4.0/

\begin{abstract}
This paper starts with the research on the value feature quantification and data spatialization of the historical and cultural district of Yuejin Road, Mianyang. Through the intuitive display of the industrial heritage value evaluation results, it can better guide the protection and management of the area. The building value evaluation system and the industrial heritage information database are established through GIS technology. On the basis of determining the 8 first-level indicators, the analytic hierarchy process is used to determine the weight of each factor, and then weighted and superimposed to form a comprehensive value evaluation map. Combined with the analysis of the value evaluation results, a corresponding strategy is proposed for the renovation and renewal of the historical and cultural block of Yuejin Road, and better promotes the development of informatization and scientificization of the protection and renovation of the historical block.
\end{abstract}

\section{Keywords}

Yuejin Road Historical and Cultural District, Industrial Heritage, GIS (Geographic Information System) Technology, AHP (Analytic Hierarchy Process)

\section{Introduction}

Since the industrial revolution in the 18th century, the industrialization of various countries has accelerated the change of the world pattern, but also changing the way of human life. The economic transition since the 1970s has gradually replaced traditional industries by high-tech industries, and traditional industrial 
facilities have begun to waste. In order to save those abandoned and destroyed mines, factories, etc., the United Nations Educational, Scientific and Cultural Organization has included these industrial sites and outstanding transport and power facilities in the World Heritage List (Liu, 2012). Those abandoned industrial heritages have new historical values. Industrial heritage as a witness of human industrial civilization, and witnessed the development of modern cities, carrying the important significance of human history, industrial heritage protection issues gradually get social attention (TICCIH, 2003). China's urban industrial heritage protection work started under the guidance of Wuxi Recommendations issued by Wuxi Forum on Cultural Heritage Protection of China hosted by the State Administration of Cultural Heritage in 2006. This report is of great milestone significance for the protection of industrial heritage in China and lays a theoretical foundation for subsequent research. Urban industrial heritage research covers architecture, history, culture, economy and other aspects, which often requires multidisciplinary cross-integration research. Previous studies have found that they mainly focus on industrial heritage tourism development, museum construction, comprehensive value evaluation, planning and transformation design (Huang et al., 2010). In recent years, the steady growth of the national economy has promoted the pace of urban industrial heritage renewal and protection. With the deepening of theoretical research and practice, some scholars try to introduce GIS technology into the study of industrial heritage. For example, Mingxing Hu constructed GIS information management system for dynamic supervision and protection of heritage in the study of Xijindu Historic District in Zhenjiang (Hu \& Wei, 2002). Xiaxian Xiong used GIS technology to qualitatively analyze the historical buildings of Shanghai Bund. She simulated different scenes of renovation and provides important experimental data for subsequent planning and design (Xiong, 2003). Tianjin Municipal Government and relevant research institutions cooperate to carry out census records of all industrial heritage in Tianjin, to build GIS information database, and update and maintain relevant industrial heritage data in real time (Xu et al., 2015). Qipeng Liao constructed the evaluation system of mining area heritage landscape, and proposed strategies for mining area landscape renewal design combined with GIS analysis method (Liao et al., 2019).

Historical and cultural blocks are an important carrier for the continuation of urban context, and their effective protection is of great significance to urban culture. Architectural value evaluation is one of the important contents of the protection of historical and cultural blocks. However, the traditional evaluation method has some shortcomings: 1) It is subjectively affected, lacks quantitative analysis of building attributes, and is not efficient; 2) Combines graphics and there are limited technical means for effective data integration, which is not convenient for collaborative sharing and information management. The spatial data processing technology of geographic information system (GIS) can better solve the above problems and provide a more scientific and reasonable value evaluation method for the buildings of historical and cultural blocks. Therefore, 
the author intends to study the comprehensive value of historical and cultural blocks of Yuejin Road in Mianyang City by GIS technology and analytic hierarchyprocess. The heritage itself has three aspects of resource element value, market economy value and environmental value. The historical value, cultural value, economic value and location value generated by radiation are 8 indicators. The industrial heritage value evaluation system is formed by 21 factors such as historical correlation, construction age and environmental safety. The data are weighted and superimposed by GIS technology to form a comprehensive value evaluation map and building classification map. The analysis results are important basis for the protection management and renovation of historical and cultural blocks of Yuejin Road. It also provides practical ideas for other heritage protection studies.

\section{Research Method}

\subsection{General Situation of Yuejin Road Historic and Cultural District}

The historical and cultural block of Yuejin Road is the place where the military electronic production plant was planned and constructed in the area of Yuejin Road in the first Five-years plan period of China. In the middle of the 20th century, four enterprises-Changhong, Juzhou, Huafeng and Fujiang Cable Power Plants, laid an important foundation to constructe electronic industrial base in period of economic difficulties. The history of these enterprises has also become a microcosm of the development of China's electronics industry. The leap road carries the historical burden of Mianyang's industrial prosperity (Jia, 2016). The area of historical and cultural protection of Mianyang City is 62 hectares, of which the core protected area is 12.6 hectares. There are rich industrial heritage resources on both sides of the Yuejin Road. The region has rich industrial heritage resources. The Yuejin Road east side of area is production, where are factory buildings and office buildings. The west is dwelling district with residential, medical, educational and municipal facilities. These buildings, known as red houses, are mainly residential buildings in the form of courtyards, built with red brick. The scope of studing is the core protected areas, and represents important urban cultural spirit (Figure 1).

\subsection{Data Collection and Processing}

Through the following three aspects of Yuejin road historical and cultural blocks related data collection: 1) field research method and questionnaire survey method of Yuejin road block field research, questionnaire collection related data. 2) Relevant data are obtained through government departments such as Natural Resources and Planning Bureau, Cultural and Tourism Bureau and local residents committees. 3) Literature review method for Mianyang local chronicles, yearbooks and related literature to collect relevant historical data Yuejin Road area. 


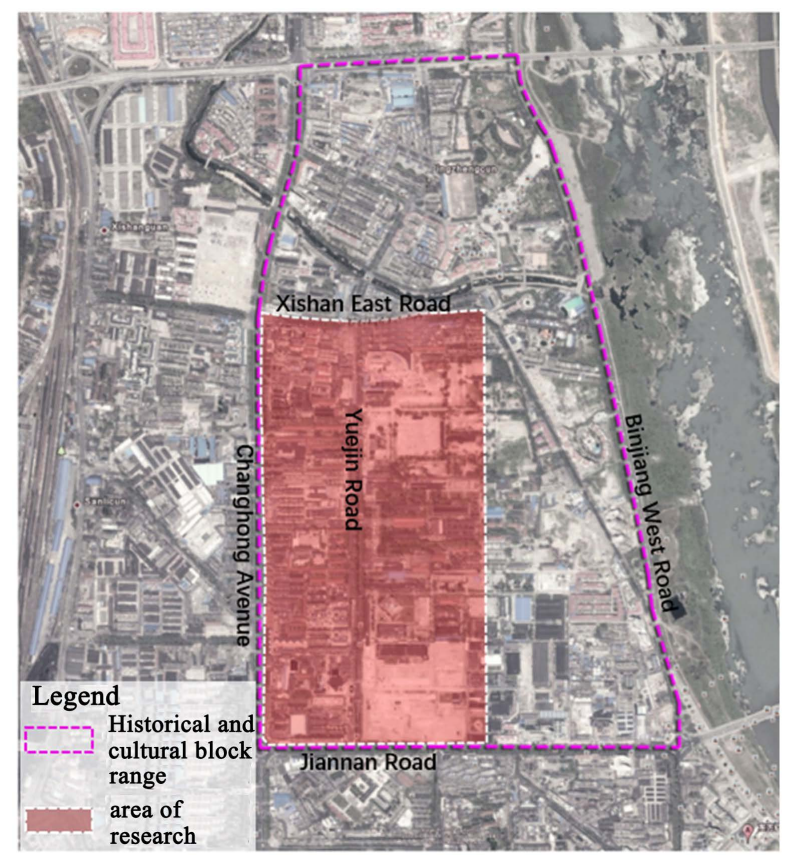

Figure 1. Research scope of Yuejin road.

\subsection{Selection of Industrial Heritage Value Evaluation Index}

Industrial heritage is composed of material heritage composed of industrial production facilities, plant buildings and structures, and intangible heritage such as corporate spiritual culture, social influence and science and technology (Liu, 2016). Many scholars emphasize the selection of elements including resource elements and redevelopment and utilization elements in heritage tourism value and landscape value research. It is also necessary to highlight the role of various factors in heritage value. By summarizing the particularity and commonness of industrial heritage value in different regions, it is found that the value evaluation index consists of three aspects: resource factor value, social and economic value and environmental value. The resource element value of industrial heritage is the core connotation of industrial heritage value and has important inheritance. It includes four elements: history, culture, art and scientific technology. It is the guarantee that heritage can be protected and adapted to the development and utilization of the new era. Socio-economic value is the three elements of society, economy and location, which determines the development and utilization prospect and direction of industrial heritage. Environmental value is an important basis for emphasizing the integrity and authenticity of the internal landscape environment and the expression of historical and regional information (Table $1)$.

\subsection{Establishment of Value Evaluation System Based on Analytic Hierarchy Process}

Through the research and analysis of relevant literature, it is found that the research methods of industrial heritage protection value and tourism development 
Table 1. Value elements of industrial heritage.

\begin{tabular}{l} 
Value of industrial heritage \\
\hline \multicolumn{1}{c}{ Value of resource elements } \\
\hline $\begin{array}{l}\text { Whether the heritage has historical inheritance is the most important, } \\
\text { which determines the historical value of the heritage. Industrial heritage } \\
\text { usually breaks the constraints of time and space and has historical } \\
\text { inheritance. Not only through the existence of buildings, structures and } \\
\text { facilities and other entities as a carrier to record the development of the } \\
\text { city in a specific historical period, but also can show the major events in } \\
\text { this history, prominent industrial technology development and other rich } \\
\text { heritage content. It is inheritable and precious. }\end{array}$ \\
$\begin{array}{l}\text { Industrial development is often a hard entrepreneurial process from } \\
\text { scratch and from difficulty to ease. In this process, outstanding struggle } \\
\text { spirit and corporate culture have emerged, which are part of industrial } \\
\text { intangible heritage. In addition, the process of industrialization is } \\
\text { accompanied by the integration of foreign culture, so the characteristics of } \\
\text { architectural style and factory form will form a unique regional culture, } \\
\text { which is also the content of cultural value inheritance of industrial } \\
\text { heritage. }\end{array}$
\end{tabular}

In the history of human art and culture, industrial aesthetics is different from other artistic expressions. Industrial aesthetics such as volume, form,

Value of art material and color are embodied in industrial architecture and machinery, which fully expresses the architectural art style, genre and technology in a specific historical stage.

Technology is the production technology summed up by the continuous test in the development of industry. It is the epitome of the level of industrial production and social development in a specific historical stage.

value of science The innovation of electronic products manufacturing technology and steel and technology casting technology in industrial production will bring great economic benefits to the society. Therefore, industrial heritage, both material and non-material heritage, has technological innovation and scientific and technological value.

$$
\text { Value of social and economic }
$$

Industrial development has a huge role in promoting urban social productivity and social production relations. Mianyang's industrial development started in the early days of new China's construction.

Value of social Industrial heritage is the emotional sustenance of local residents to the past life, and also the value embodiment of industrial production projects' contribution to society.

The original function of industrial heritage has not met the needs of current social development. Reasonable functional changes can increase regional economic development and become a catalyst for urban economic growth. Industrial buildings are mainly divided into production buildings

Value of economic and living buildings. In particular, production buildings have the advantages of large internal space span, high storey height, strong and durable building quality, and good preservation of the main body. Re-use and renovation can meet the requirements of multiple functions, and the reuse value of industrial heritage is well reflected.

Factory location is located in the railway, highway, river and other convenient traffic location. Because of the small scale of urban

Value of location construction, factories were usually located near the edge of the city. With the expansion of urban development, the location of industrial heritage has gradually become the central area of the city, and its location value is obvious in economy, politics and culture. 


\section{Continued}

\begin{tabular}{l} 
Value of environment \\
$\begin{array}{l}\text { Whether the internal landscape environment of industrial sites has } \\
\text { integrity and authenticity is an important way to express historical and } \\
\text { regional information. Usually within the heritage huge tower crane, } \\
\text { abandoned rails and plants and other landscape features have important } \\
\text { value. And the surrounding landscape environment and other factors will } \\
\text { also affect the reuse of industrial heritage. }\end{array}$ \\
\hline
\end{tabular}

value are Delphi method, Analytic Hierarchy Process (AHP), Contingent Valuation Method (CVM) and BP neural network mathematical model of genetic algorithm. The analytic hierarchy process is more mature in the evaluation of industrial heritage value. Therefore, based on the analytic hierarchy process, this study evaluates the historical and cultural blocks of Yuejin Road. The evaluation indicators are divided into three directions: the value of heritage resources elements, socio-economic value and environmental value, which are 8 first-level indicators and 21 second-level indicators. Finally, the system structure model of industrial heritage comprehensive value evaluation including target layer, comprehensive evaluation layer, project evaluation layer and factor evaluation layer is formed (Figure 2).

\subsection{Determination and Analysis of Evaluation Index Weight}

Through the analytic hierarchy process to determine the weight of each index. In the establishment of a good model tree for each factor pairwise comparison scale (scale type: 1 - 9) for judgment matrix analysis. Yaahp10.3 software was used to test the consistency of the collected data, and the consistency of the matrix was determined to be 0.037 , which met the requirements. Then the weight of each evaluation factor was calculated (Table 2).

In the project evaluation layer, the weight of historical value is $30.84 \%$, and the cultural value, social value and technological value are $19.28 \%, 13.84 \%$ and $10.57 \%$ respectively. This shows that in the comprehensive value evaluation of industrial heritage, more attention is paid to the material and non-material elements of industrial heritage, which is the core of industrial heritage. The weight of location value is the smallest. At present, the urban transportation modes are diversified, and the influence of market location on the value of industrial heritage is reduced. Therefore, the protection and inheritance of the original elements should be paid attention to in the renewal and transformation of industrial heritage.

\subsection{Establishment of Calculation Model for Comprehensive Value Evaluation of Industrial Heritage}

The comprehensive value evaluation system of industrial heritage is constructed by analytic hierarchy process, including the construction age and historical correlation degree, and then the relevant weights of the indicators are determined. 


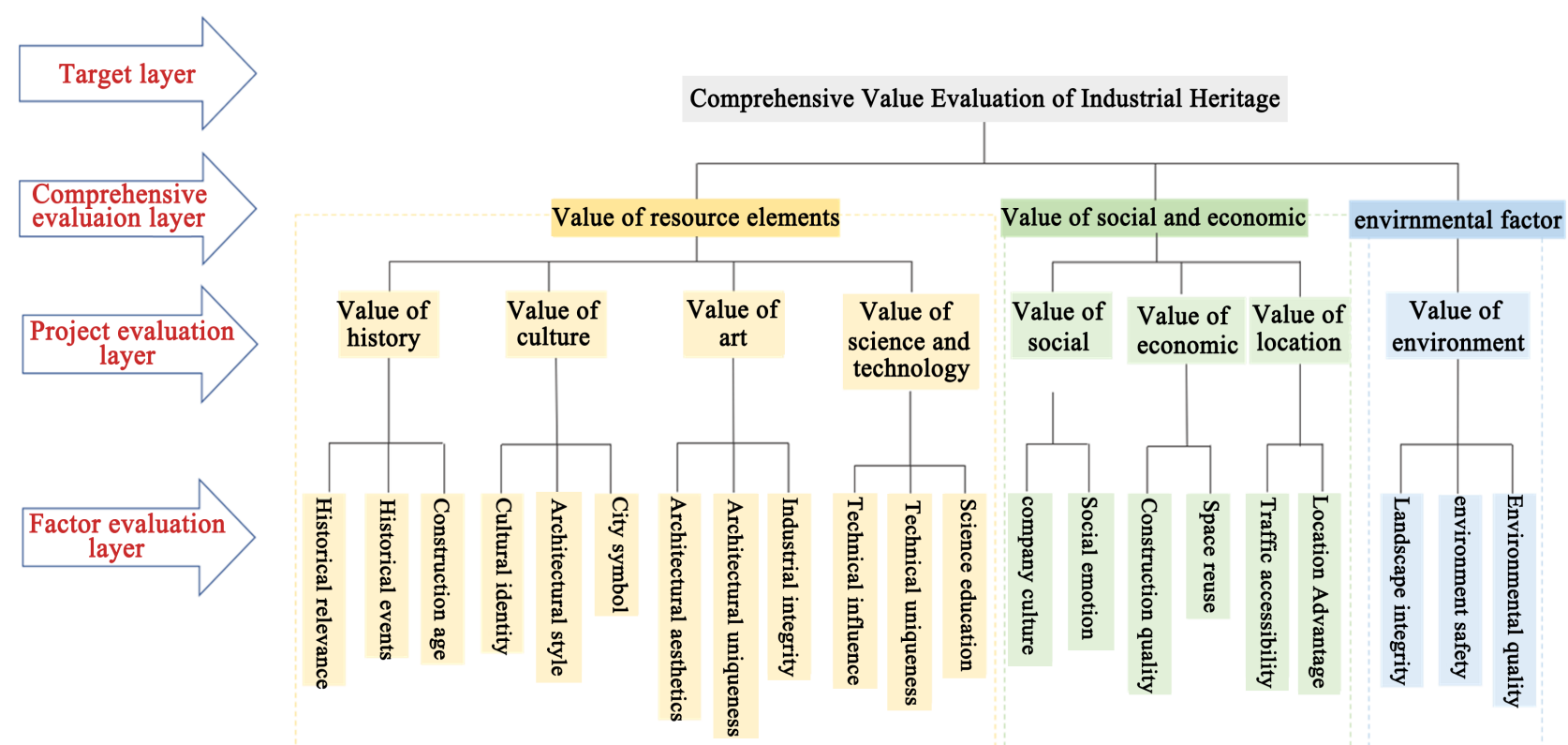

Figure 2. Industrial heritage comprehensive value evaluation system structure model.

Table 2. Weight of evaluation factors in project evaluation layer.

\begin{tabular}{cc}
\hline Evaluation factor & Weight \\
\hline Value of history & $30.84 \%$ \\
Value of culture & $19.28 \%$ \\
Value of social & $13.84 \%$ \\
value of science and technology & $10.57 \%$ \\
Value of economic & $10.12 \%$ \\
Value of art & $8.78 \%$ \\
Value of environment & $4.02 \%$ \\
Value of location & $2.54 \%$ \\
\hline
\end{tabular}

The value of industrial heritage is affected by many factors. It is necessary to determine the index score of the subject by combining the relevant information collected and the scoring criteria developed.

The application formula determines the comprehensive evaluation model of industrial heritage:

$$
Y=W * U
$$

$Y$ indicates the value of the object to be evaluated (industrial heritage). $W$ is the weight of the index elements in the evaluation system, $U$ is the score under each index. After calculation and statistics, the industrial heritage buildings in the core area of Yuejin Road Historic and Cultural District are graded and evaluated, which lays a good foundation for the subsequent construction of GIS database and diversified analysis. 


\section{Results and Discussion}

\subsection{Construction of GIS Industrial Heritage Database}

The biggest feature of GIS technology is the establishment of a spatial database, which can more conveniently obtain data resources, more efficiently store and manage various types of data, and can use the database to draw various current sub-maps required for industrial heritage protection (Yan, 2019). In addition, GIS also has powerful analysis capabilities that can analyze and process all kinds of complex data, and the processing results are accurate and intuitive. The evaluation of the value of industrial heritage includes elements such as environment and geography, which need to be stored efficiently and quickly in management. The core functions of GIS in industrial heritage renewal planning include data acquisition, storage, editing, analysis, and spatial decision support. Therefore, entering the industrial heritage survey information collected by the survey into the GIS industrial heritage information database can provide strong support for subsequent value evaluation and government management and maintenance.

In the industrial heritage, grid data is mainly spatial data with old industrial buildings, structures, ancillary facilities, supporting facilities, site topography, existing roads, and the relationship with surrounding buildings. Grid data have the characteristics of simple data structure, large amount of data, and strong ability to express spatial transformation. Collecting data is to quantify these continuous earth space into discrete pixels, such as remote sensing image data, scanning map into grid data. The database of industrial heritage projects is mainly composed of two parts. One part is the graphic files made by Auto CAD and other software, including buildings, roads and other converted into GIS shape files. The other part is the attribute data. After the graphic file is converted into GIS, it is necessary to input the collected industrial heritage information, such as building height, building age, building quality and so on. Based on this framework, these data and content can be updated in real time (Figure 3).

Through this method, the survey data is transformed into attribute data and input into GIS industrial heritage database. It can change the complex situation of industrial heritage projects, and the physical form and spatial relationship of various buildings, structures and process facilities have no ready-made documents for use. In the process of using GIS database, managers update and modify the database in time according to the actual situation of specific projects, providing data and technical support for subsequent heritage protection (Liu \& Zhao, 2020).

\subsection{Single Factor Evaluation Assignment}

The input attribute data is converted into grid data, and the index of project evaluation layers is divided into five evaluation dimensions: excellent, good, general, poor and poor corresponding values 5, 4, 3, 2 and 1 . The evaluation of the index layer is based on the elements of the factor evaluation layer and the 


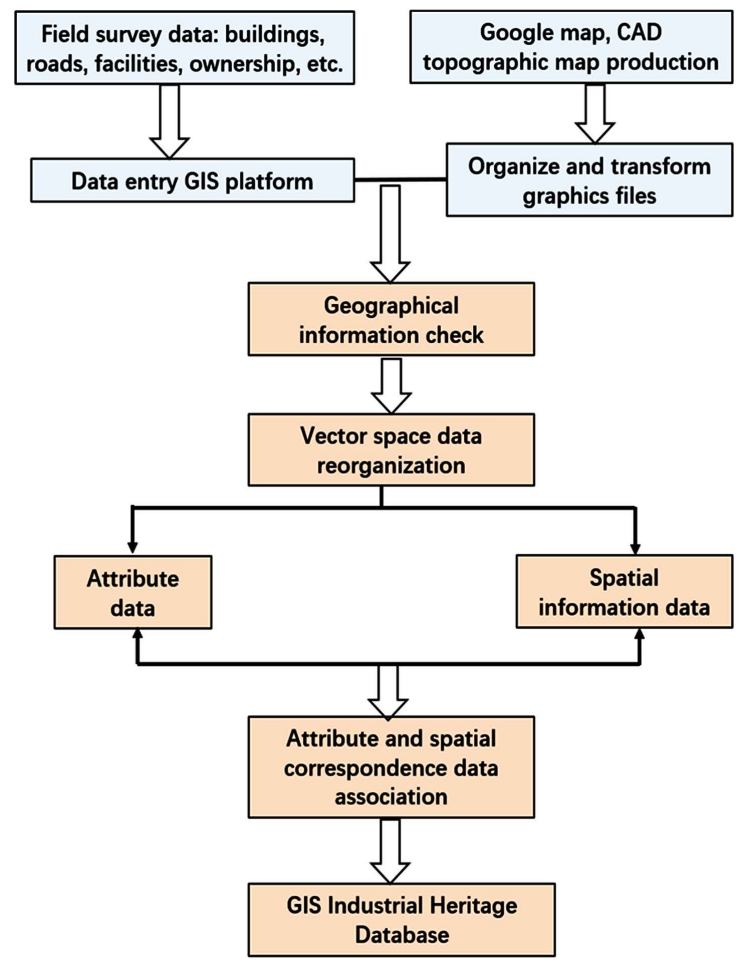

Figure 3. Construction of GIS industrial heritage database flowchart.

scoring basis (Table 3), and then assigns one-to-one corresponding values to each building in the GIS platform according to the evaluation classification requirements. Finally, the Data is visualized by GIS to generate evaluation map of index layer (Figure 4). Through single-factor evaluation and analysis, it is found that the historical value, cultural value, artistic value, technological value, social value and economic value of the Yuejin Road block are mainly production and office buildings, such as workshops and office buildings. Most of these buildings It is of good quality, distinctive design, and public use functions.

\subsection{Multi-Factor Weighted Overlay Evaluation}

Through the calculation formula of the comprehensive value of the heritage: $\mathrm{Y}=$ $\mathrm{W} * \mathrm{U}$, the weight value of each index factor is calculated, and the comprehensive value of the multifactor influence is calculated. Then use the spatial overlay function of GIS to analyze the data, and obtain the comprehensive value distribution map of the industrial heritage and the building classification map (Figure 5) (Zhang et al., 2012).

Through the analysis of the industrial heritage value system, the value evaluation map of the historical and cultural block of Yuejin Road is consistent with the situation of field investigation. Through the analysis of the industrial heritage value system, the value evaluation map of the historical and cultural block of Yuejin Road is consistent with the situation of field investigation. Through the analysis of the industrial heritage value system, the value evaluation map of the historical and cultural block of Yuejin Road is consistent with the situation of 


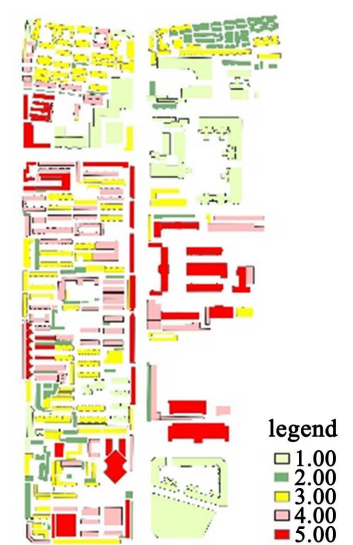

(1) Historical value analysis chart

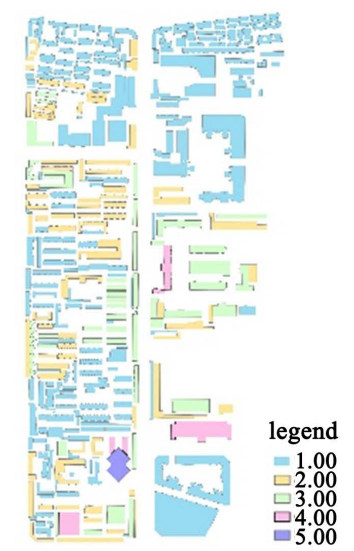

(5) Social value analvsis chart

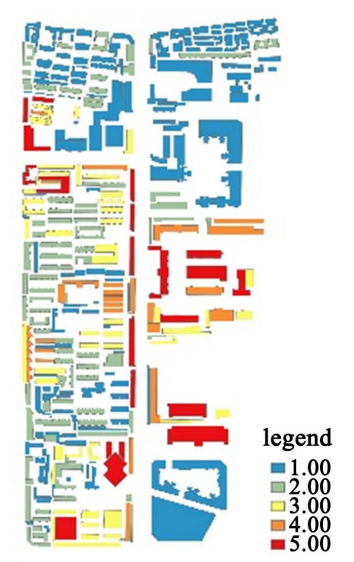

(2) Cultural value analysis chart

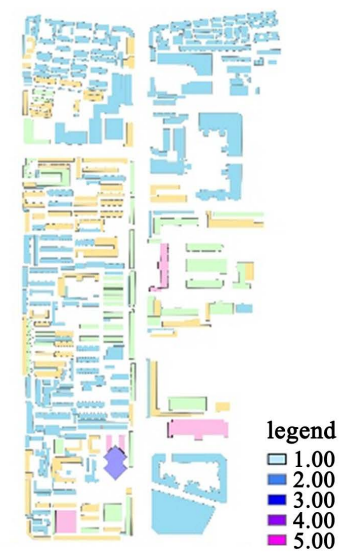

(6) Fconomic value analvsis chart

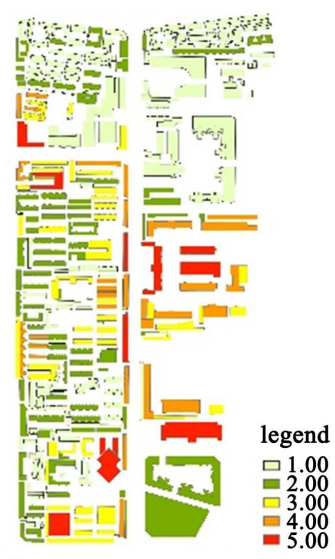

(2) Artistic value analysis chart

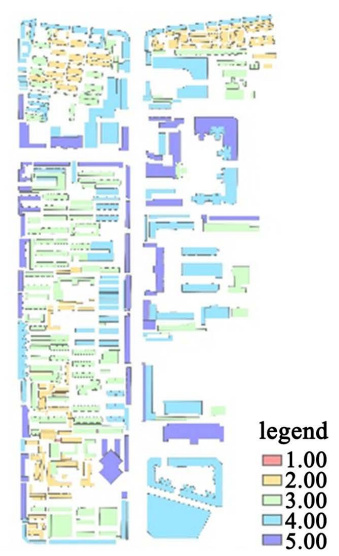

(7) Location value analvsis chart

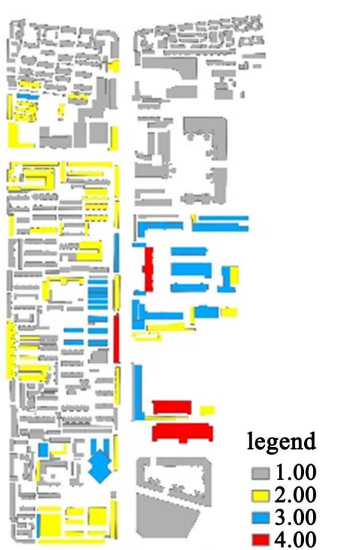

(4) Technological value analysis chart

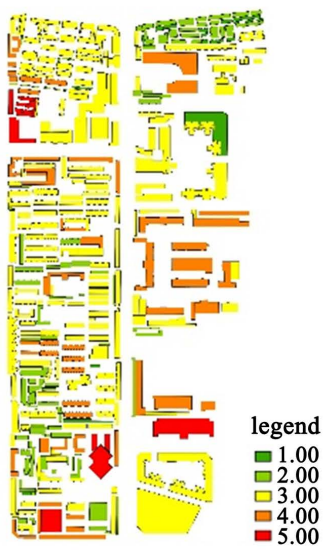

(8) Environmental value analvsis chart

Figure 4. The single-factor value evaluation map of the heritage of the historical and cultural block of Yuejin Road.
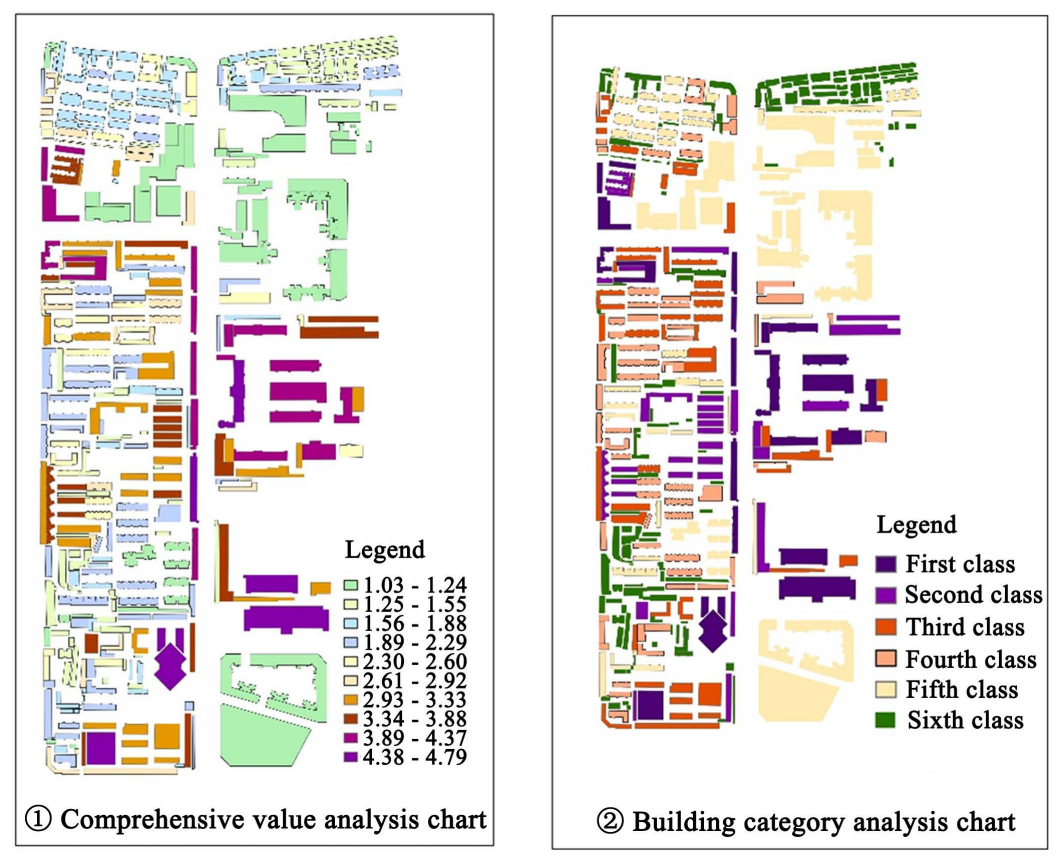

Figure 5. Comprehensive evaluation map of heritage value and building classification map of the heritage of the historical and cultural block of Yuejin Road. 
Table 3. Classification criteria of single factor evaluation.

\begin{tabular}{|c|c|c|c|c|}
\hline index factor & $\begin{array}{l}\text { evaluation } \\
\text { weight }\end{array}$ & evaluation classification & score & Remarks \\
\hline \multirow{5}{*}{ Value of history } & \multirow{5}{*}{$30.84 \%$} & $\begin{array}{l}\text { The historical value is high. The building was built after 1950, with rich historical } \\
\text { connotations. }\end{array}$ & 5 & \multirow{20}{*}{$\begin{array}{l}\text { Value of } \\
\text { resource } \\
\text { elements }\end{array}$} \\
\hline & & The historical value is high. The building was built after 1960, with rich historical data. & 4 & \\
\hline & & $\begin{array}{l}\text { The historical value is average. The building was built after 1970, with some historical } \\
\text { information. }\end{array}$ & 3 & \\
\hline & & The historical value is low. The building was built after 1980 , with litter related history. & 2 & \\
\hline & & The historical value is low. The building was built after 2000 . & 1 & \\
\hline \multirow{5}{*}{ Value of culture } & \multirow{5}{*}{$19.28 \%$} & $\begin{array}{l}\text { The cultural value is high. The building has rich heritage resources and is a } \\
\text { symbol of the city. }\end{array}$ & 5 & \\
\hline & & $\begin{array}{l}\text { The cultural value is high. The building has rich heritage resources and has } \\
\text { a strong social and cultural influence. }\end{array}$ & 4 & \\
\hline & & $\begin{array}{l}\text { The cultural value is average. The building has some heritage resources, } \\
\text { which can have a cultural impact on the surrounding area. }\end{array}$ & 3 & \\
\hline & & The cultural value is low. The building has some heritage resources. & 2 & \\
\hline & & The cultural value is low. The building was built after 2000 . & 1 & \\
\hline \multirow{5}{*}{ Value of art } & \multirow{5}{*}{$8.78 \%$} & $\begin{array}{l}\text { The artistic value is high. The heritage such as material heritage and technical } \\
\text { craftsmanship can express the characteristics of the culture and art of the times. }\end{array}$ & 5 & \\
\hline & & The artistic value is high. The heritage is rich in culture and art. & 4 & \\
\hline & & The artistic value is average. Heritage has some cultural and artistic resources. & 3 & \\
\hline & & $\begin{array}{l}\text { The artistic value is low. The heritage such as buildings and structures have } \\
\text { characteristics of the times. }\end{array}$ & 2 & \\
\hline & & The artistic value is low. The building was built after 2000 . & 1 & \\
\hline \multirow{5}{*}{$\begin{array}{l}\text { value of science } \\
\text { and technology }\end{array}$} & \multirow{5}{*}{$10.57 \%$} & $\begin{array}{l}\text { The value of science and technology is high. Scientific process technology is } \\
\text { unique and has strong scientific and technological influence. }\end{array}$ & 5 & \\
\hline & & $\begin{array}{l}\text { The value of science and technology is high. The heritage has scientific and } \\
\text { technological influence, and the significance of popular science education is strong. }\end{array}$ & 4 & \\
\hline & & $\begin{array}{l}\text { The value of science and technology is average. The heritage has some scientific } \\
\text { and technological influence. }\end{array}$ & 3 & \\
\hline & & $\begin{array}{l}\text { The value of science and technology is low. The heritage has litter scientific and } \\
\text { technological influence. }\end{array}$ & 2 & \\
\hline & & The value of science and technology is low. The building was built after 2000 . & 1 & \\
\hline \multirow{5}{*}{ social value } & \multirow{5}{*}{$13.84 \%$} & $\begin{array}{l}\text { The social value is high. Heritage has a rich cultural connotation of the spirit of } \\
\text { the times, and is an important carrier of social emotions. }\end{array}$ & 5 & \multirow{6}{*}{$\begin{array}{l}\text { Value of } \\
\text { social and } \\
\text { economic }\end{array}$} \\
\hline & & The social value is high. Heritage can express the spirit of the times and social emotions. & 4 & \\
\hline & & $\begin{array}{l}\text { The social value is average. Heritage can represent corporate culture and social } \\
\text { emotions. }\end{array}$ & 3 & \\
\hline & & The social value is low. Heritage has not corporate culture and social emotions. & 2 & \\
\hline & & The social value is low. The building was built after 2000 . & 1 & \\
\hline economic Value & $10.12 \%$ & $\begin{array}{l}\text { The economic value is high. The building is an industrial building or a warehouse } \\
\text { building with open interior space. The quality of the building is good and the } \\
\text { surrounding traffic is convenient. }\end{array}$ & 5 & \\
\hline
\end{tabular}




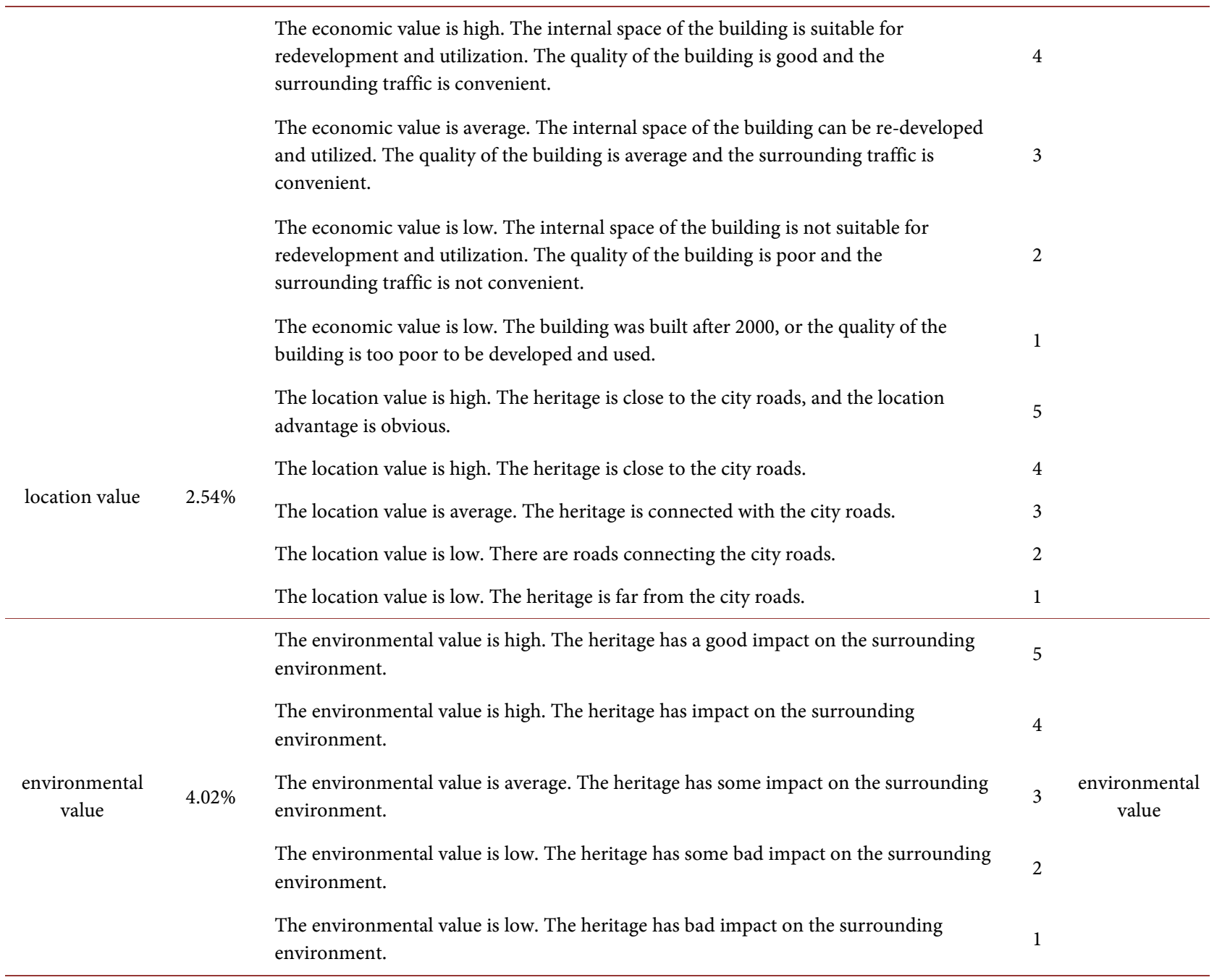

field investigation. Through the analysis of the industrial heritage value system, the value evaluation map of the historical and cultural block of Yuejin Road is consistent with the situation of field investigation.

\subsection{Protection and Remediation Strategies}

Combining the relevant requirements of the urban master plan and the historical and cultural heritage protection plan proposed by Mianyang City, a total of 399 buildings within the scope of the study are divided into six categories, and each type of building will have a corresponding protection and renovation method. The buildings are classified by the natural discontinuity classification method in GIS software, the scores are automatically identified and the interval is classified, and similar target values are appropriately grouped. After calculation, the lowest score for the building is 1.03 , the highest score is 4.79 , the total is 857.78 , and the average score is 2.144 . The comprehensive score is divided into six categories with the goal of maximizing the difference between the categories, and the boundary is automatically set at the position where the score difference 
is relatively large. However, because some of the buildings in the research area are newly built after 2000, the value scores of historical, cultural and artistic aspects are low, and the comprehensive value score is also lower than the average score. This part of the building needs to be reclassified to retain the status quo without making changes.

After conducting a classification study on the historical and cultural blocks of Yuejin Road, it is proposed that for the first and second types of buildings with

Table 4. Renovation and renewal strategy of classified buildings.

\begin{tabular}{|c|c|c|c|c|}
\hline $\begin{array}{l}\text { classified } \\
\text { buildings }\end{array}$ & $\begin{array}{l}\text { Comprehensive } \\
\text { value segment }\end{array}$ & $\begin{array}{c}\text { Number } \\
\text { of buildings }\end{array}$ & Features & Renovation and renewal strategy \\
\hline
\end{tabular}

This type of industrial heritage is listed for protection and included in the list of urban

Such buildings are mainly workshops, office buildings and living buildings. They are the First class $\quad 4.06-4.79 \quad 26 \quad$ main carriers of historical and cultural connotations, and are unique in style and culture. historical buildings to delimit the scope of protection. By adhering to the principle of original appearance protection and regular repairs and maintenance, it can be appropriately developed and utilized, and structures with poor environmental impact within the protection area can be dismantled.

The buildings include workshops, storage buildings, mixed commercial and residential buildings and residential buildings in living
This type of heritage is listed for protection and included in the list of historical buildings in the city. It is mainly repaired and repaired by restoring the original appearance and can be appropriately developed and utilized. areas. It has typical characteristics of the historical era and has important historical and cultural values.

Second class $\quad 3.30-3.96 \quad 34$

Third class $\quad 2.63-3.26$

49

The buildings include workshops, storage buildings, mixed commercial and residential buildings and residential buildings in living areas. It has some characteristics of the historical era and historical and cultural values.
The appearance of the building cannot be significantly modified, and the appearance elements such as the volume of the building and the roof form should be controlled to make full use of the value attached to the building. The functional space inside the building is fully improved and utilized to enhance vitality.

The building is mainly renovated based on the architectural style and characteristics of the Yuejin Road block, and then the use of building materials, decoration styles and other aspects are coordinated to maintain the original residential function.

Fourth class $\quad 2.05-2.60 \quad 62 \quad \begin{aligned} & \text { and education in the living area, and the } \\ & \text { characteristics of the historical era are not } \\ & \text { obvious. }\end{aligned}$

\begin{tabular}{|c|c|c|c|}
\hline Fifth class & $1.55-2.03$ & 135 & $\begin{array}{l}\text { This type of buildings are mainly residential } \\
\text { buildings in living areas and commercial } \\
\text { residential communities built after } 2000 \text {. } \\
\text { The residential communities are of good } \\
\text { quality and have a good impact on the } \\
\text { surrounding environment. }\end{array}$ \\
\hline
\end{tabular}

Most of these buildings are residential buildings that are illegally constructed in the Sixth class $\quad 1.03-1.53 \quad 93 \quad$ living area and have a poor impact on the surrounding environment, and have major potential fire safety hazards.
Taking into account the needs of urban development and the needs of citizens' lives, this type of building is reserved without any changes. Those with poor impact on the surrounding environment need to be demolished.
These buildings should be demolished. The development of the block should be considered, and the functions should be reasonably optimized. 
typical historical era characteristics and important cultural values, the protection area should be delineated, listed for protection, and included in the relevant protection list, and renovated and updated. The strategy is mainly to restore the original appearance and repair the vacancies, regular maintenance and so on. For the third and fourth types of buildings with certain characteristics of the historical era, mainly based on the principle of harmony between the architectural style of the block, the exterior decoration and other aspects are improved and refurbished, and the internal space is fully utilized for functional replacement to enhance the vitality of the block. Regarding the fifth type of buildings that are mainly reserved, most of them were built after 2000, taking into account the needs of urban development and construction costs, etc., without making changes, and retaining the current status. For the sixth type of buildings, they are mainly privately constructed and chaotically constructed, which have poor impact on the surrounding environment and generate hidden fire safety hazards. They need to be demolished, and then other functions are planned and arranged (Table 4).

\section{Conclusion}

This paper takes the historical and cultural district of Yuejin Road in Mianyang City as the research object, extracts the index elements of the heritage based on the analytic hierarchy process to construct the comprehensive value evaluation system of the industrial heritage; uses GIS technology to collect and organize the spatial data and attribute data of the heritage buildings to construct the GIS industry The heritage information database, combined with the value evaluation system for weighted overlay analysis, provides a new idea for the value evaluation of industrial heritage. This research method avoids the problems of traditional evaluation methods, and also provides detailed and intuitive spatial and geographic information and relevant protection and rectification suggestions for the protection and utilization of historical buildings and the construction and management of historical and cultural blocks. At the same time, managers can update and modify the database through the GIS industrial heritage information database, provide data and technical support for subsequent heritage protection, and make more contributions to the informatization and scientific management of historical and cultural blocks.

\section{Conflicts of Interest}

The authors declare no conflicts of interest regarding the publication of this paper.

\section{References}

Hu, M. X., \& Wei, D. (2002). GIS-Based Protection and Management Information System of Zhenjiang Xijindu Historic District. Planner, No. 3, 71-73.

Huang, L. M., Li, C. B., \& Huang, H. (2010). Research on Countermeasures for the Protection and Utilization of Industrial Heritage in Urban Renewal. Planning Innovation: 
Proceedings of 2010 China Urban Planning Annual Conference, 4477-4482.

Jia, D. F. (2016). Analysis on the Protection and Utilization of Historical Blocks in Urban Renewal: Taking the Reconstruction of the "Red House" in the Historical and Cultural Block of Yuejin Road in Mianyang City as an Example. Architectural Engineering Technology and Design, No. 19, 36-38.

Liao, Q. P., Chen, R., \& Huang, S. Z. (2019). Landscape Evaluation of Abandoned Mining Areas Based on Fuzzy Comprehensive Evaluation and GIS Method. Geological Science and Technology Information, 38, 241-250.

Liu, B. Y. (2012). A Review of the Research on Chinese Industrial Architectural Heritage. New Architecture, No. 2, 4-9.

Liu, Y. (2016). Research on the Protection and Reuse Strategy of My Country's Industrial Architectural Heritage in the Post-Industrial Era. Tianjin: Tianjin University.

Liu, Z. G., \& Zhao, Y. P. (2020). Research on the Value Information Record of Industrial Heritage in the Protection of Xi'an Historic Buildings-Taking Xi'an Metallurgical Machinery Factory as an Example. Urban Architecture, 17, 11-16.

TICCIH (2003). Nizhny Tagil Charter for the Industrial Heritage.

Xiong, X. X. (2003). The Application of GIS in the Management of Cultural Heritage I. The Bund's Historical Style Protection. Take the Protected Area as an Example. Shanghai: Tongji University.

Xu, S. B., Zhang, J. H., Nobuo, A., \& Wu, C. (2015). Research on the Construction of Key Urban Industrial Heritage GIS Database-Take Tianjin as an Example. "Industrial Architecture” 2015 Supplement I: Industrial Architecture Magazine, 138-143.

Yan, R. J. (2019). Research on Urban Industrial Heritage Renewal Planning Based on GIS. Xi'an: Xi'an Technological University.

Zhang, D. D., Jiang, L. Q., \& Zhang, D. (2012). Research on the Value Evaluation of Industrial Heritage Tourism Resources Based on AHP-Taking Wuxi City Industrial Heritage Tourism Resources as an Example. Jiangsu Business Forum, No. 7,126-129. 